\title{
Calcium and vitamin D intakes may be positively associated with brain lesions in depressed and non-depressed elders
}

\author{
Martha E. Payne ${ }^{a, b,{ }^{*},}$ John J. B. Anderson ${ }^{C}$, and David C. Steffens ${ }^{a}$ \\ aDepartment of Psychiatry and Behavioral Sciences, Duke University Medical Center, Durham, NC, USA \\ (MEP, DCS) \\ bNeuropsychiatric Imaging Research Laboratory, Duke University Medical Center, 2200 West Main Street, \\ Suite B210, Durham, NC, USA (MEP) \\ cDepartment of Nutrition, The University of North Carolina at Chapel Hill, CB \#7461, Chapel Hill, NC, USA \\ $(J J B A)$
}

\begin{abstract}
Studies indicate that diet and vascular calcification may be related to the occurrence of brain lesions, although the importance of dietary calcium and vitamin $\mathrm{D}$ has not been investigated. The objective of this study was to test the hypothesis that calcium and vitamin D intakes would be positively associated with brain lesion volumes in elderly individuals with and without late-life depression. A cross sectional study was performed as part of a longitudinal clinical study of late-life depression. Calcium and vitamin D intakes were assessed in 232 elderly subjects (95 with current or prior depression, 137 without depression) using a Block 1998 food frequency questionnaire. Calcium, vitamin D, and kilocalorie intake were determined. Brain lesion volumes were calculated from magnetic resonance imaging scan. Subjects were age 60 years or over. Calcium and vitamin D intakes were significantly and positively correlated with brain lesion volume $(\mathrm{p}<0.05$ and $\mathrm{p}<0.001$, respectively). In two separate multivariable models, controlling for age, hypertension, diabetes, heart disease, group (depression/comparison), lesion load (high/low), and total kilocalories, these positive associations remained significant ( $<<0.05$ for calcium; $p<0.001$ for vitamin $\mathrm{D})$. In conclusion, calcium and vitamin D consumption were associated with brain lesions in elderly subjects, even after controlling for potentially explanatory variables. These associations may be due to vascular calcification or other mechanism. The possibility of adverse effects of high intakes of calcium and vitamin D needs to be further explored in longitudinal studies of elderly subjects.
\end{abstract}

\section{Keywords}

calcium; vitamin D; lesions; elderly; brain; diet; human

\footnotetext{
*Corresponding Author: Martha E. Payne, PhD, RD, MPH, Neuropsychiatric Imaging Research Laboratory, Duke University Medical Center, 2200 West Main Street, Suite B210, Durham, NC 27705 USA, Tel.: (919) 416-7543 Fax: (919) 416-7547, Email: martha.payne@duke.edu.

This work was presented at Experimental Biology 2007 (ASN program), Washington DC

Publisher's Disclaimer: This is a PDF file of an unedited manuscript that has been accepted for publication. As a service to our customers we are providing this early version of the manuscript. The manuscript will undergo copyediting, typesetting, and review of the resulting proof before it is published in its final citable form. Please note that during the production process errors may be discovered which could affect the content, and all legal disclaimers that apply to the journal pertain.
} 


\section{Introduction}

Brain lesions seen on magnetic resonance imaging (MRI) (Fig. 1) are indicative of damage to gray and white matter [1] and are associated both cross-sectionally and longitudinally with cognitive dysfunction [2,3], dementia [4], stroke [5], late-life depression [6], and functional impairment [7]. Lesions are known to be associated with both the persistence and worsening of depressive symptoms $[6,8]$. Research into the causes of brain lesions is critical to understanding the occurrence and progression of numerous afflictions of late-life.

Calcium dysregulation is important in chronic diseases such as osteoporosis and atherosclerosis, as well as in nervous system disorders such as dementia and depression [912]. Calcification of vascular smooth muscle occurs with aging, renal disease, and atherosclerosis, and has been associated with brain lesions and cognitive impairment [13,14]. The importance of diet to brain lesions remains uncertain. In small studies high doses of calcium and vitamin D have been associated with vascular calcification [15,16]. High intakes of calcium were found to be associated with coronary artery calcification in a small sample $(n=39)$ of young adults with end-stage renal disease [15]. Administration to rats $(n=47)$ of calcitriol, the hormonal form of vitamin D, was found to cause vascular calcification [16].

Depressed individuals may be especially susceptible to the effects of calcium dysregulation; reports confirm a higher prevalence of calcification [17] and disturbances of calcium metabolism in depressed patients $[9,18]$. In addition, dietary calcium itself has been found to promote learned helplessness, an animal model of depression, in rats [19]. One study of elderly subjects found carotid atherosclerosis to be related to brain lesions only in those with depression [20]. Our group previously found that high-fat dairy consumption was positively associated with brain lesion volumes in depressed elders [21]. However, since high-fat dairy was correlated with overall dairy consumption, we speculated that other dairy nutrients, particularly those related to calcium metabolism, might be responsible for the dairy-lesion association.

Examination of a possible relationship between dietary calcium and vitamin $\mathrm{D}$, and brain lesions is critical for a number of reasons. The aging of the population will likely increase the prevalence of brain lesions and their sequelae, including cognitive impairment and depression. Late-life depression, considered to be related to obesity [22] and the metabolic syndrome [23,24], may also increase secondary to rising obesity rates [25]. These population changes come at a time when calcium and vitamin D supplementation is being encouraged in an effort to prevent osteoporosis and other diseases of late-life [26,27]. In addition, vitamin D intake recommendations are being revised upwards [28]. The impact of these dietary changes on brain health and psychological well-being needs to be examined.

The present study was conducted in a group of geriatric individuals with and without depression. The goal was to determine whether calcium and vitamin $\mathrm{D}$ intakes were associated with brain lesion volume. The hypothesis was that reported intakes of both calcium and vitamin $\mathrm{D}$ would be positively correlated with brain lesion volume. In addition, we hypothesized that depression might accentuate this association because of differences in calcium metabolism and vascular calcification among depressives $[17,18]$.

\section{Methods and materials}

\subsection{Design}

This cross-sectional project occurred within a larger longitudinal clinical study of depression in older adults (Longitudinal Study of Depression in Later Life and the Conte Center for the Neuroscience of Depression). Subjects have been followed for this project for up to 14 years; the nutrition assessment was paired with the closest available MRI and clinical assessment 
data. The rationale for this project was to determine if an association exists between dietary calcium and vitamin $\mathrm{D}$, and brain lesion volumes in depressed and non-depressed elders.

\subsection{Sample}

This sample included patients of the Duke University Psychiatric Service with a primary diagnosis of major depression at study baseline and comparison subjects recruited from the Aging Center Subject Registry at Duke University [29]. Enrollment was restricted to those 60 years or older, and those who could speak and write English.

Exclusion criteria included a concurrent diagnosis of a major psychiatric or neurological illness, significant cognitive impairment (as indicated by a Mini-Mental State Examination score of less than 24 out of 30) [30], and metal in body (contraindicated for MRI). In addition, subjects with severe depression symptomatology were excluded because of concerns about subject burden. This criterion did not require a specific depression rating cut-off but was instead determined by the treating psychiatrist on a case-by-case basis.

Comparison subjects were required to have a non-focal neurological examination, self-report of no neurological or depressive illness, and no evidence of a depression diagnosis based on the Diagnostic Interview Schedule portion of the Duke Depression Evaluation Schedule [31].

After complete description of the study to the subjects, written informed consent was obtained. This research protocol has been reviewed and approved by the Duke University Medical Center Institutional Review Board.

\subsection{Treatment}

Depression subjects received individualized treatment from a psychiatrist [29]. Most received antidepressant medications which include selective serotonin reuptake inhibitors. Some subjects received electroconvulsive treatment or psychotherapy. Depression subjects were seen quarterly by their study psychiatrist, or more often if clinically indicated. Comparison subjects received no psychiatric treatment or medical intervention but they did come to clinic yearly for research assessments.

\subsection{Measures}

Assessments included psychiatric [29], medical [31], nutrition [32], and imaging [33] measures. At baseline and yearly thereafter a trained interviewer administered the Duke Depression Evaluation Schedule (DDES) [34] in-person to each subject. The DDES, a composite diagnostic interview instrument, included sections of the NIMH (National Institute of Mental Health) Diagnostic Interview Schedule which assesses depression, and was enriched with items on physical health [31]. Clinical assessments, including the Montgomery-Asberg Depression Rating (MADRS), were performed at study baseline and quarterly thereafter [35]. Nutrition assessments were administered annually [32]. Brain MRI was performed every two years, starting at study baseline [33].

2.4.1. Nutrition protocol-The nutrition subproject has been described previously [32]. The 1998 Block Food Frequency Questionnaire (FFQ) was used for nutrition assessment. This tool is an updated version of the FFQ developed by Gladys Block at the National Cancer Institute. The Block FFQ was designed to estimate the components of a person's total dietary intake over the preceding year [36]. Returned questionnaires were checked for completeness and rejected if more than 15 food items were skipped. Intake estimates included total kilocalories, calcium from foods, vitamin D from foods, calcium from dietary supplements, and vitamin D from dietary supplements. Food sources of calcium include dairy products (milk, cheese, yogurt, and ice cream), beans, fortified orange juice, almonds, and some green 
vegetables [37]. Vitamin D food sources include fortified milk, eggs, fish, fortified orange juice, fortified cereals, and mushrooms [37].

2.4.2. Magnetic resonance imaging (MRI)—Subjects were imaged with a 1.5 Tesla whole-body MRI system (Signa, GE Medical Systems, Milwaukee, WI) under an IRBapproved protocol. The pulse sequence parameters have been described previously [33]. The MR images were processed for lesion volumes by blinded analysts (blinded to all identifying information, including depression diagnosis and dietary intake) in the Neuropsychiatric Imaging Research Laboratory (NIRL). In addition, the scans were qualitatively assessed for the presence of lesions by a neuroradiologist.

2.4.2.1. Lesion assessment (qualitative): Both $\mathrm{T} 1$ - and $\mathrm{T} 2$-weighted pulse sequences were visually examined for incidental findings and lesion ratings. Lesion ratings performed for this study have been described previously [33]. Ratings included the following Coffey scale items:

Deep white matter hyperintensity (lesion-intense regions within the white matter tracts of cerebrum): 0 - absent; 1 - punctate foci; 2 - beginning confluence of foci; 3 - large confluent areas

Subcortical gray matter hyperintensity (lesion-intense regions within the basal ganglia and other subcortical gray matter structures): 0 - absent; 1 - punctate; 2 -multi-punctate; 3 - diffuse

Subjects who received a rating of 2 or higher on either subcortical gray or deep white hyperintensities were categorized as having high lesion load; otherwise, they were categorized as having low lesion load. This criterion has been used previously for distinguishing vascular (high lesion load) depression from non-vascular depression [38]. Lesion load for this study was assessed from the earliest available MRI.

2.4.2.2. Quantitative brain assessments (including lesion volumes): A dual-echo fast spinecho axial acquisition was used for volumetric measurement of brain structures, including gray and white matter lesions. NIRL image processing procedures have been described previously [33]. The method is a supervised, semi-automated method that uses the multiple MR contrasts available to identify different tissue classifications through a 'seeding' process wherein a trained analyst manually selects pixels in each tissue type that are to be identified (such as gray matter, white matter, cerebrospinal fluid, lesions, background). Gray and white matter lesion areas were selected based upon a set of rules that allow trained analysts to reliably select lesion regions. Periventricular lesions were defined as regions that were contiguous with lateral ventricle and did not extend into the white matter tracts. These lesions were classified as white matter lesions. Deep white matter lesions were located in the white matter tracts and may or may not have adjoined periventricular lesions. Subcortical gray matter lesions were defined as lesions within the basal ganglia or thalamus. Total lesion volumes were comprised of both gray matter lesions and white matter lesions, although white matter lesions predominated.

\subsection{Analyses}

All statistical analyses were run using JMP software, version 4.0 (SAS Institute, Inc., Cary, $\mathrm{NC}$ ). A significance level of 0.05 was used for all analyses except for selection of covariates (see below for details).

Statistical analyses used lesion volumes from the MRI closest to the time of the nutrition assessment. For most subjects the MRI and nutrition assessments were separated by less than one year. In order to minimize the time interval, either assessment could precede the other. Self-report of hypertension, diabetes, and heart disease was obtained from the closest annual DDES instrument. Analyses first assessed the potential for responder bias. Bivariate 
comparisons were made between individuals with acceptable FFQs ("responders") and those who either did not return a questionnaire or who returned an unacceptable one (together categorized as "nonresponders"). Variables examined included age, sex, race, lesion volume, hypertension, diabetes, heart disease, and group (depression or comparison). Bivariate comparisons between responder category (responder/nonresponder) and covariates were conducted using (a) Chi-squared test if the covariates were categorical (sex, race, hypertension, diabetes, heart disease, and group), and (b) t-test if the variables were continuous (age and lesion volume).

Simple regression analyses [39] were performed to examine the relationships between lesion volume and each of the two nutrients of interest, total vitamin D and total calcium, which were calculated by combining food and dietary supplement estimates for each nutrient.

To examine the diet and lesion relationships while controlling for potential confounders, two separate multivariable regression models [39] with lesion volume as the dependent variable were run, using either total vitamin D or total calcium as the independent variable of interest. Prior to examining the multivariable associations, covariates were selected for inclusion by backwards stepwise regression. A cutoff of $\mathrm{p}>0.2$ was used for exclusion of covariates. Covariates examined in this way included age, sex, race (white/nonwhite), hypertension (yes/ no), diabetes (yes/no), heart disease (yes/no), BMI $\left(\mathrm{kg} / \mathrm{m}^{2}\right)$, total energy (kcals), group (depression/comparison), lesion load (high/low), and group*lesion load (interaction term). Once covariates were selected and either vitamin D or calcium was added as an independent variable, interaction terms were examined and included in final model if $\mathrm{p}<0.05$. Interaction terms of interest were vitamin $\mathrm{D}$ or calcium and group (depression/comparison), and vitamin $\mathrm{D}$ or calcium and lesion load (high/low). Lastly, a multivariable regression model was run which included both vitamin $\mathrm{D}$ and calcium.

\section{Results}

\subsection{Description of sample}

A total of 287 subjects were determined to be eligible to receive an FFQ questionnaire, of whom $232(81 \%)$ successfully completed it. The earliest FFQ assessment was used for all except three subjects (1\%). For those three subjects who had returned an unacceptable initial questionnaire, the earliest acceptable subsequent FFQ was used. Nonrespondents (those who did not return an FFQ or returned an unacceptable one) did not differ from respondents in terms of age, sex, race, lesion volume, hypertension, diabetes, or heart disease, but were more likely to have been in the depression group. All subjects had complete data except for six subjects who had missing BMI and eleven subjects who did not respond to the question on vitamin use.

\subsection{Group differences}

Sample characteristics $(\mathrm{n}=232)$ are shown in Table 1 . The study group is presented as a whole and also divided into four groups based upon group (depression/comparison) and lesion load (high/low). Nutrient intake estimates for calcium and vitamin D are presented as totals, and as amounts from foods and dietary supplements. Groups exhibited significant differences in age, hypertension, BMI, calcium intake, and lesion volume. Mean lesion volume ( \pm standard deviation) was $6.1 \mathrm{~mL}( \pm 8.0$ ), with a range of 0.7 to 61.8 . A Shapiro-Wilks test for normality was performed for total lesion volume. It indicated that lesion volume was not normally distributed ( $\mathrm{W}=0.55, \mathrm{p}<0.001$ ). A new variable for the logarithmic transformation (natural $\log$ ) of lesion volume (logLESION) was created, which visually had an improved distribution although was also not normal $(\mathrm{W}=0.94, \mathrm{p}<0.001)$. Geometric mean for lesion volume was included in Table 1 as a measure of central tendency that is less prone to distortion from outliers. In addition, geometric means may be easier to interpret than logarithmic values given that they 
have the same units as the original variable (lesion volume). Bivariate analyses between $\operatorname{logLESION}$ and both vitamin $\mathrm{D}$ and calcium were performed. Both vitamin $\mathrm{D}(\beta=0.0008$, SE $=0.0002, \mathrm{t}=3.7, \mathrm{p}<0.001)$ and calcium $(\beta=0.0002, \mathrm{SE}=0.00008, \mathrm{t}=2.1, \mathrm{p}=0.04)$ were significantly positively associated with logLESION.

\subsection{Multivariable regression models}

Backwards stepwise regression for selection of covariates led to elimination (at $p>0.2$ ) of the following variables: BMI, group*lesion load (interaction term), sex, and race. Covariates included in the final models were age, hypertension, diabetes, heart disease, total kilocalories, group (depression/comparison), and lesion load. Calcium by group, calcium by lesion load, vitamin D by group, and vitamin D by lesion load interaction terms were evaluated and were found not to be statistically significant, although calcium by lesion load was close to significance at $\mathrm{p}=0.055$. A multivariable model which examined the association between $\operatorname{logLESION}$ and calcium while controlling for covariates found calcium intake to be positively associated with lesion volume ( $\beta=0.0001, \mathrm{SE}=0.00006, \mathrm{t}=2.28, \mathrm{p}=0.02)$. Similarly vitamin $\mathrm{D}$ intake was found to be positively associated with lesion volume $(\beta=0.0006, \mathrm{SE}=0.0002$, $\mathrm{t}=3.56, \mathrm{p}<0.001)$. Calcium and vitamin $\mathrm{D}$ were confirmed to be collinear $(\mathrm{p}<0.0001)$. A final model was run which included both nutrients: $\log L E S I O N=\beta_{0}+\beta_{1}$ Calcium $+\beta_{2}$ Vitamin $\mathrm{D}+\beta_{3}$ Age $+\beta_{4}$ Hypertension $+\beta_{5}$ Diabetes $+\beta_{6}$ Heart Disease $+\beta_{7}$ Kilocalories $+\beta_{8}$ Group + $\beta_{9}$ Lesion Load $+\varepsilon$. Vitamin D retained a positive association with lesion volume $(\beta=0.0005$, $\mathrm{SE}=0.0002, \mathrm{t}=2.74, \mathrm{p}=0.007)$ while calcium intake was no longer associated with lesion volume $(\beta=0.00004, \mathrm{SE}=0.00007, \mathrm{t}=0.5, \mathrm{p}=0.6)$. Age, diabetes, and lesion load were positively associated with lesion volume in all three models.

\subsection{Summary}

Dietary calcium and vitamin D were significantly positively associated with brain lesion volume is both bivariate and multivariable models.

\section{Discussion}

The finding of an association between calcium, vitamin $\mathrm{D}$, and brain lesions is consistent with the hypothesized role of calcium dysregulation in the etiology of brain lesions. Intakes of calcium and vitamin $\mathrm{D}$ were found to be significantly positively associated with brain lesion volume among elderly individuals. After controlling for potential confounders, calcium and vitamin $\mathrm{D}$ remained significantly associated with lesion volume. These findings raise the possibility that calcium and vitamin D may have detrimental effects on brain health, and highlight the need for longitudinal investigations. Potential mechanisms to explain these relationships include vascular calcification and neurotoxic effects (Fig. 2).

The linkage of calcification and brain lesions has been previously reported. A sub-sample of the Rotterdam Study of elderly ( $\mathrm{n}=111$ ) showed a positive association between carotid calciumcontaining atherosclerotic plaques and cerebral white matter lesions [14]. A combined analysis of the Rotterdam and Zoetermeer Studies confirmed the finding of a significant positive association between carotid atherosclerosis and white matter lesions [40]. The Cardiovascular Health Study (CHS) found a two-fold increase in the prevalence of brain infarcts in elderly individuals $(n=3,502)$ with calcified carotid plaques [41]. The CHS found that coronary artery calcification was also associated with white matter lesions, other brain abnormalities, and cognitive impairment [13].

Vascular calcification was reported as early as the $19^{\text {th }}$ century when Virchow observed that calcium deposits within the vasculature comprised bone-like tissue [42]. Multiple mechanisms have been proposed to explain the etiology of vascular calcification, with bone biology, calcium 
homeostasis, and the inflammatory response having interactive roles [12,43-45]. Specific mechanisms by which dietary calcium and vitamin D promote vascular calcification are unclear. Although each of these nutrients has independent roles, high intake of either may result in increased availability of calcium ions for uptake by vascular tissue, especially among older adults [46,47]. A high calcium diet has been shown to increase serum calcium concentrations [46]. Calcium concentrations, in turn, have been positively associated with mineralization of vascular smooth muscle [48], carotid artery plaque thickness [49], and coronary artery disease burden [50].

Vitamin D in its hormonal form, calcitriol, functions in the regulation of calcium homeostasis, partially by modifying intestinal absorption of calcium and partly by actions on osteoblasts [47]. Calcitriol receptors and activities have been demonstrated in vascular smooth muscle [51] and may mediate calcification [52,53].

Calcium may also have direct effects on neuronal health (Fig. 2). Calcium dysregulation may promote neurotoxic mechanisms when membrane permeability to calcium is increased [10]. Indirectly, calcium entry blockers have been shown in rats to ameliorate brain energy metabolism during reperfusion which may protect the brain from ischemic damage [54]. Data for humans, however, are not clear.

The finding of a significant relationship between brain lesions and vitamin $\mathrm{D}$, but not calcium (in the combined model), may indicate that dietary vitamin $\mathrm{D}$ has direct or indirect effects on vascular smooth muscle cells. Demer has speculated that exogenous vitamin D may preferentially affect the vasculature [55]. However, it is unclear how dietary vitamin D (cholecalciferol) would affect the vasculature without first being converted to calcitriol $(1,25$ dihydroxycholecalciferol), the active hormonal form. Given the relatively high calcium intakes in the present study, it is likely that this conversion would be down-regulated [47].

The failure to find depression or lesion load to modify the diet and brain lesion relationship may mean that calcium and vitamin $\mathrm{D}$ are associated with brain lesions across a variety of conditions and severity in the elderly. Alternatively, this failure may indicate an insufficient sample size to detect such an association. Also of note is that diabetes mellitus was found to be significantly associated with lesion volumes in the multivariable models. We speculate that the diabetes and lesion association is related to sub-optimal renal function, as the damaged kidneys may be responsible for excessive calcium retention. However, laboratory measures of renal function were not available so this hypothesis could not be tested.

This study has several limitations including the modest sample size. The cross-sectional design precludes confirmation of an etiological effect of diet on brain lesions, but it does permit hypothesis generation. The length of time likely required for development of brain lesions combined with a lack of historical dietary data make interpretation of any association even more difficult. An epidemiological rather than a biochemical approach was employed for this study so readers should be cautioned that discussion of physiological mechanisms is purely speculative. This project did not incorporate any measurements of calcium metabolism, vitamin D status, vascular calcification, sun exposure, or renal or hepatic functioning. Because of these shortcomings, we cannot conclude that dietary factors were related to brain lesions because of any specific mechanism. The Block FFQ may be insufficient to detect dietary differences between individuals across the spectrum of brain lesion volumes, due to problems associated with self-report and the inherently high intra-individual to inter-individual variation of nutrient intakes, particularly for micronutrients. In addition, the estimate of vitamin D intake from dietary supplements is not as precise as for calcium supplements, given the lack of specificity about vitamin D-containing supplements. Use of medications including bisphosphonates, 
diuretics, and calcium channel blockers were not examined. Finally, generalizability of these findings to the overall population of elderly individuals is unknown.

This preliminary report indicates the importance of longitudinally evaluating the wide-ranging effects of dietary calcium and vitamin D, especially in elderly subjects. While it would be premature to condemn calcium and vitamin $\mathrm{D}$ supplementation, it would be equally irresponsible not to recognize the potentially damaging nervous or vascular effects of high intakes of these nutrients, particularly at levels currently promoted by health professionals. The recommended Dietary Reference Intakes (DRIs) for individuals over age 50 are $1200 \mathrm{mg}$ for calcium and between 400 and 600 IU for vitamin D [56], and vitamin D recommendations are currently being increased [28]. Mean intakes among our study population were approximately equal to the DRI for calcium (mean $=1280 \mathrm{mg}$ ) and were lower than current recommendations for vitamin D (mean = $341 \mathrm{IU}$ ). Use of dietary supplements accounted for over one-third of calcium and one-half of vitamin D intakes in this study sample.

In conclusion, evidence of a positive association between brain lesion volume and intakes of both calcium and vitamin $\mathrm{D}$ was found among elderly individuals with and without depression in this preliminary study. These results are consistent with an association between calcium dysregulation and brain lesions. These findings need to be confirmed in a larger sample, particularly one which includes a wide range of conditions and lesion severities. In addition, future studies should incorporate biochemical measures. Evaluation of the wide-ranging effects on health of high calcium and vitamin D intakes are particularly critical at a time when both nutrients are being promoted for their potential protective effects for osteoporosis and other conditions. Randomized clinical trials are needed in order to confirm etiological relations between these micronutrients and brain lesions, and to determine whether vascular calcification or other mechanism explains such a relationship.

\section{Acknowledgements}

The authors wish to thank the participants of this research project for their dedication to furthering knowledge of latelife depression and aging. The authors also acknowledge the following individuals from Duke University Medical Center for their assistance with subject recruitment and assessment: Denise F. Messer, Cortnee W. Pierce, and Carrie B. Dombeck. The authors also thank D. Messer for performing the lesion volume measurements and for editorial assistance, and Carl F. Pieper and Maragatha Kuchibhatla for their expert statistical guidance.

This project was funded by the following National Institute of Mental Health grants: MH40159, MH54846, MH60451, and $\mathrm{MH} 70027$.

\section{List of abbreviations}

\section{DDES}

Duke Depression Evaluation Schedule

FFQ

Food Frequency Questionnaire

MRI

Magnetic Resonance Imaging

NIRL

Neuropsychiatric Imaging Research Laboratory

\section{References}

1. Taylor WD, Payne ME, Krishnan KR, Wagner HR, Provenzale JM, Steffens DC, MacFall JR. Evidence of white matter tract disruption in MRI hyperintensities. Biol Psychiatry 2001;50:179-83. [PubMed: 11513816] 
2. de Groot JC, de Leeuw FE, Oudkerk M, van Gijn J, Hofman A, Jolles J, Breteler MM. Cerebral white matter lesions and cognitive function: the Rotterdam Scan Study. Ann Neurol 2000;47:145-51. [PubMed: 10665484]

3. van den Heuvel DM, Ten Dam VH, de Craen AJ, Admiraal-Behloul F, Olofsen H, Bollen EL, Jolles J, Murray HM, Blauw GJ, Westendorp RG, van Buchem MA. Increase in periventricular white matter hyperintensities parallels decline in mental processing speed in a non-demented elderly population. $\mathbf{J}$ Neurol Neurosurg Psychiatry 2006;77:149-53. [PubMed: 16421114]

4. Vermeer SE, Prins ND, den Heijer T, Hofman A, Koudstaal PJ, Breteler MM. Silent brain infarcts and the risk of dementia and cognitive decline. N Engl J Med 2003;348:1215-22. [PubMed: 12660385]

5. Vermeer SE, Hollander M, van Dijk EJ, Hofman A, Koudstaal PJ, Breteler MM. Silent brain infarcts and white matter lesions increase stroke risk in the general population: the Rotterdam Scan Study. Stroke 2003;34:1126-9. [PubMed: 12690219]

6. Steffens DC, Krishnan KR, Crump C, Burke GL. Cerebrovascular disease and evolution of depressive symptoms in the cardiovascular health study. Stroke 2002;33:1636-44. [PubMed: 12053004]

7. Steffens DC, Bosworth HB, Provenzale JM, MacFall JR. Subcortical white matter lesions and functional impairment in geriatric depression. Depress Anxiety 2002;15:23-8. [PubMed: 11816049]

8. Steffens DC, Helms MJ, Krishnan KR, Burke GL. Cerebrovascular disease and depression symptoms in the cardiovascular health study. Stroke 1999;30:2159-66. [PubMed: 10512922]

9. Plein H, Berk M, Eppel S, Butkow N. Augmented platelet calcium uptake in response to serotonin stimulation in patients with major depression measured using Mn2+ influx and 45Ca2+ uptake. Life Sci 2000;66:425-31. [PubMed: 10670830]

10. Demuro A, Mina E, Kayed R, Milton SC, Parker I, Glabe CG. Calcium dysregulation and membrane disruption as a ubiquitous neurotoxic mechanism of soluble amyloid oligomers. J Biol Chem 2005;280:17294-300. [PubMed: 15722360]

11. Foster TC, Kumar A. Calcium dysregulation in the aging brain. Neuroscientist 2002;8:297-301. [PubMed: 12194497]

12. Doherty TM, Asotra K, Fitzpatrick LA, Qiao JH, Wilkin DJ, Detrano RC, Dunstan CR, Shah PK, Rajavashisth TB. Calcification in atherosclerosis: bone biology and chronic inflammation at the arterial crossroads. Proc Natl Acad Sci U S A 2003;100:11201-6. [PubMed: 14500910]

13. Rosano C, Naydeck B, Kuller LH, Longstreth WT Jr, Newman AB. Coronary artery calcium: associations with brain magnetic resonance imaging abnormalities and cognitive status. J Am Geriatr Soc 2005;53:609-15. [PubMed: 15817006]

14. Bots ML, van Swieten JC, Breteler MM, de Jong PT, van Gijn J, Hofman A, Grobbee DE. Cerebral white matter lesions and atherosclerosis in the Rotterdam Study. Lancet 1993;341:1232-7. [PubMed: 8098390]

15. Goodman WG, Goldin J, Kuizon BD, Yoon C, Gales B, Sider D, Wang Y, Chung J, Emerick A, Greaser L, Elashoff RM, Salusky IB. Coronary-artery calcification in young adults with end-stage renal disease who are undergoing dialysis. N Engl J Med 2000;342:1478-83. [PubMed: 10816185]

16. Bas A, Lopez I, Perez J, Rodriguez M, Aguilera-Tejero E. Reversibility of calcitriol-induced medial artery calcification in rats with intact renal function. J Bone Miner Res 2006;21:484-90. [PubMed: 16491297]

17. Tiemeier H, van Dijck W, Hofman A, Witteman JC, Stijnen T, Breteler MM. Relationship between atherosclerosis and late-life depression: the Rotterdam Study. Arch Gen Psychiatry 2004;61:369-76. [PubMed: 15066895]

18. Konopka LM, Cooper R, Crayton JW. Serotonin-induced increases in platelet cytosolic calcium concentration in depressed, schizophrenic, and substance abuse patients. Biol Psychiatry 1996;39:708-13. [PubMed: 8731458]

19. Trulson ME, Arasteh K, Ray DW. Effects of elevated calcium on learned helplessness and brain serotonin metabolism in rats. Pharmacol Biochem Behav 1986;24:445-8. [PubMed: 2422668]

20. Chen CS, Chen CC, Kuo YT, Chiang IC, Ko CH, Lin HF. Carotid intima-media thickness in lateonset major depressive disorder. Int J Geriatr Psychiatry 2006;21:36-42. [PubMed: 16323250]

21. Payne ME, Haines PS, Chambless LE, Anderson JJB, Steffens DC. Food group intake and brain lesions in late-life vascular depression. Int Psychogeriatr 2007;19:295-305. [PubMed: 17054820] 
22. Roberts RE, Deleger S, Strawbridge WJ, Kaplan GA. Prospective association between obesity and depression: evidence from the Alameda County Study. Int J Obes Relat Metab Disord 2003;27:51421. [PubMed: 12664085]

23. Heiskanen TH, Niskanen LK, Hintikka JJ, Koivumaa-Honkanen HT, Honkalampi KM, Haatainen KM, Viinamaki HT. Metabolic syndrome and depression: a cross-sectional analysis. J Clin Psychiatry 2006;67:1422-7. [PubMed: 17017829]

24. Skilton MR, Moulin P, Terra JL, Bonnet F. Associations Between Anxiety, Depression, and the Metabolic Syndrome. Biol Psychiatry. 2007

25. Kuczmarski RJ, Flegal KM, Campbell SM, Johnson CL. Increasing prevalence of overweight among US adults. The National Health and Nutrition Examination Surveys, 1960 to 1991. Jama 1994;272:205-11. [PubMed: 8022039]

26. Ma J, Johns RA, Stafford RS. Americans are not meeting current calcium recommendations. Am J Clin Nutr 2007;85:1361-6. [PubMed: 17490974]

27. Benton MJ, White A. Osteoporosis: recommendations for resistance exercise and supplementation with calcium and vitamin D to promote bone health. J Community Health Nurs 2006;23:201-11. [PubMed: 17064230]

28. Vieth R, Bischoff-Ferrari H, Boucher BJ, Dawson-Hughes B, Garland CF, Heaney RP, Holick MF, Hollis BW, Lamberg-Allardt C, McGrath JJ, Norman AW, Scragg R, Whiting SJ, Willett WC, Zittermann A. The urgent need to recommend an intake of vitamin D that is effective. Am J Clin Nutr 2007;85:649-50. [PubMed: 17344484]

29. Steffens DC, Welsh-Bohmer KA, Burke JR, Plassman BL, Beyer JL, Gersing KR, Potter GG. Methodology and preliminary results from the neurocognitive outcomes of depression in the elderly study. J Geriatr Psychiatry Neurol 2004;17:202-11. [PubMed: 15533991]

30. Folstein MF, Folstein SE, McHugh PR. "Mini-mental state" A practical method for grading the cognitive state of patients for the clinician. J Psychiatr Res 1975;12:189-98. [PubMed: 1202204]

31. Robins LN, Helzer JE, Croughan J, Ratcliff KS. National Institute of Mental Health Diagnostic Interview Schedule. Its history, characteristics, and validity. Arch Gen Psychiatry 1981;38:381-9. [PubMed: 6260053]

32. Payne ME, Hybels CF, Bales CW, Steffens DC. Vascular nutritional correlates of late-life depression. Am J Geriatr Psychiatry 2006;14:787-95. [PubMed: 16943175]

33. Payne ME, Fetzer DL, MacFall JR, Provenzale JM, Byrum CE, Krishnan KR. Development of a semi-automated method for quantification of MRI gray and white matter lesions in geriatric subjects. Psychiatry Res 2002;115:63-77. [PubMed: 12165368]

34. Landerman R, George LK, Campbell RT, Blazer DG. Alternative models of the stress buffering hypothesis. Am J Community Psychol 1989;17:625-42. [PubMed: 2627025]

35. Montgomery SA, Asberg M. A new depression scale designed to be sensitive to change. $\mathrm{Br} \mathrm{J}$ Psychiatry 1979;134:382-9. [PubMed: 444788]

36. Block G. Dietary assessment issues related to cancer for NHANES III. Vital Health Stat 4 1992:2431. [PubMed: 1375410]

37. Gebhardt, SE.; Thomas, RG. Nutritive Value of Foods. Beltsville, MD: U.S. Department of Agriculture; 2002.

38. Krishnan KR, Hays JC, Blazer DG. MRI-defined vascular depression. Am J Psychiatry 1997;154:497-501. [PubMed: 9090336]

39. Kleinbaum, DG.; Kupper, LL.; Muller, KE. Applied Regression Analysis and Other Multivariable Methods. 2. Belmont, CA: Duxbury Press; 1988.

40. de Leeuw FE, de Groot JC, Bots ML, Witteman JC, Oudkerk M, Hofman A, van Gijn J, Breteler MM. Carotid atherosclerosis and cerebral white matter lesions in a population based magnetic resonance imaging study. J Neurol 2000;247:291-6. [PubMed: 10836622]

41. Manolio TA, Burke GL, O’Leary DH, Evans G, Beauchamp N, Knepper L, Ward B. Relationships of cerebral MRI findings to ultrasonographic carotid atherosclerosis in older adults : the Cardiovascular Health Study. CHS Collaborative Research Group. Arterioscler Thromb Vasc Biol 1999;19:356-65. [PubMed: 9974419]

42. Virchow, R. Cellular Pathology: As Based upon Physiological and Pathological Histology. Chance, Frank, translator. New York, NY: 1863. p. 404-08.1971 
43. Giachelli CM. Vascular calcification mechanisms. J Am Soc Nephrol 2004;15:2959-64. [PubMed: 15579497]

44. Demer LL. Vascular calcification and osteoporosis: inflammatory responses to oxidized lipids. Int $\mathbf{J}$ Epidemiol 2002;31:737-41. [PubMed: 12177011]

45. Demer LL, Tintut Y. Mineral exploration: search for the mechanism of vascular calcification and beyond: the 2003 Jeffrey M. Hoeg Award lecture. Arterioscler Thromb Vasc Biol 2003;23:1739-43. [PubMed: 12958041]

46. Martini L, Wood RJ. Relative bioavailability of calcium-rich dietary sources in the elderly. Am J Clin Nutr 2002;76:1345-50. [PubMed: 12450902]

47. Anderson, JJB. Minerals. In: Mahan, LK.; Escott-Stump, S., editors. Krause's Food, Nutrition, and Diet Therapy. 11. Philadelpha, PA: Saunders; 2004. p. 120-63.

48. Yang H, Curinga G, Giachelli CM. Elevated extracellular calcium levels induce smooth muscle cell matrix mineralization in vitro. Kidney Int 2004;66:2293-9. [PubMed: 15569318]

49. Rubin MR, Rundek T, McMahon DJ, Lee HS, Sacco RL, Silverberg SJ. Carotid artery plaque thickness is associated with increased serum calcium levels: The Northern Manhattan study. Atherosclerosis. 2006

50. Nunes JP, Faria Mdo S, Maciel MJ, Garcia JM. Correlation between plasma calcium and coronary artery disease burden in patients with preserved renal function. Int J Cardiol 2005;98:363-6. [PubMed: 15686797]

51. Merke J, Hofmann W, Goldschmidt D, Ritz E. Demonstration of 1,25(OH)2 vitamin D3 receptors and actions in vascular smooth muscle cells in vitro. Calcif Tissue Int 1987;41:112-4. [PubMed: 2820558]

52. Inoue T, Kawashima H. 1,25-Dihydroxyvitamin D3 stimulates 45Ca2+-uptake by cultured vascular smooth muscle cells derived from rat aorta. Biochem Biophys Res Commun 1988;152:1388-94. [PubMed: 2837186]

53. Jono S, Nishizawa Y, Shioi A, Morii H. 1,25-Dihydroxyvitamin D3 increases in vitro vascular calcification by modulating secretion of endogenous parathyroid hormone-related peptide. Circulation 1998;98:1302-6. [PubMed: 9751679]

54. Krieglstein J, Weber J. Calcium entry blockers protect brain energy metabolism against ischemic damage. Adv Exp Med Biol 1986;200:243-51. [PubMed: 3799312]

55. Demer LL. A skeleton in the atherosclerosis closet. Circulation 1995;92:2029-32. [PubMed: 7554176]

56. Institute of Medicine. Dietary Reference Intakes for Calcium, Phosphorus, Magnesium, Vitamin D, and Fluoride. Washington, DC: National Academy Press; 1997. 

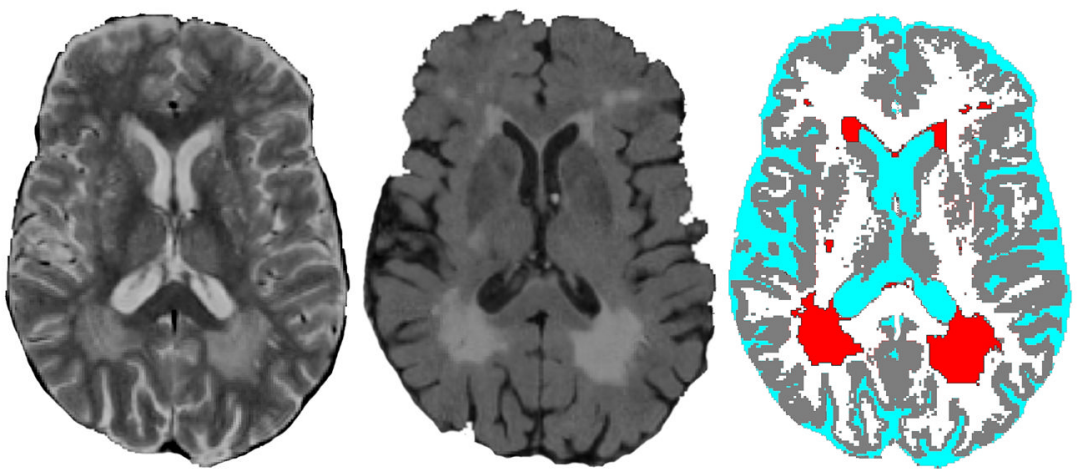

Figure 1. Brain lesions seen on magnetic resonance imaging (MRI) ${ }^{1}$

${ }^{1}$ Lesions, believed to be of ischemic origin, occur with aging but particularly with late-life depression. These lesions may damage mood regulation pathways (leading to depression) or cause cognitive impairment. Lesions are shown here on a proton density image (left), fluidattenuated inversion recovery (FLAIR) image (center), and tissue classification image (right). Lesions are red on tissue classification image. Images are courtesy of the Neuropsychiatric Imaging Research Laboratory at Duke University. 


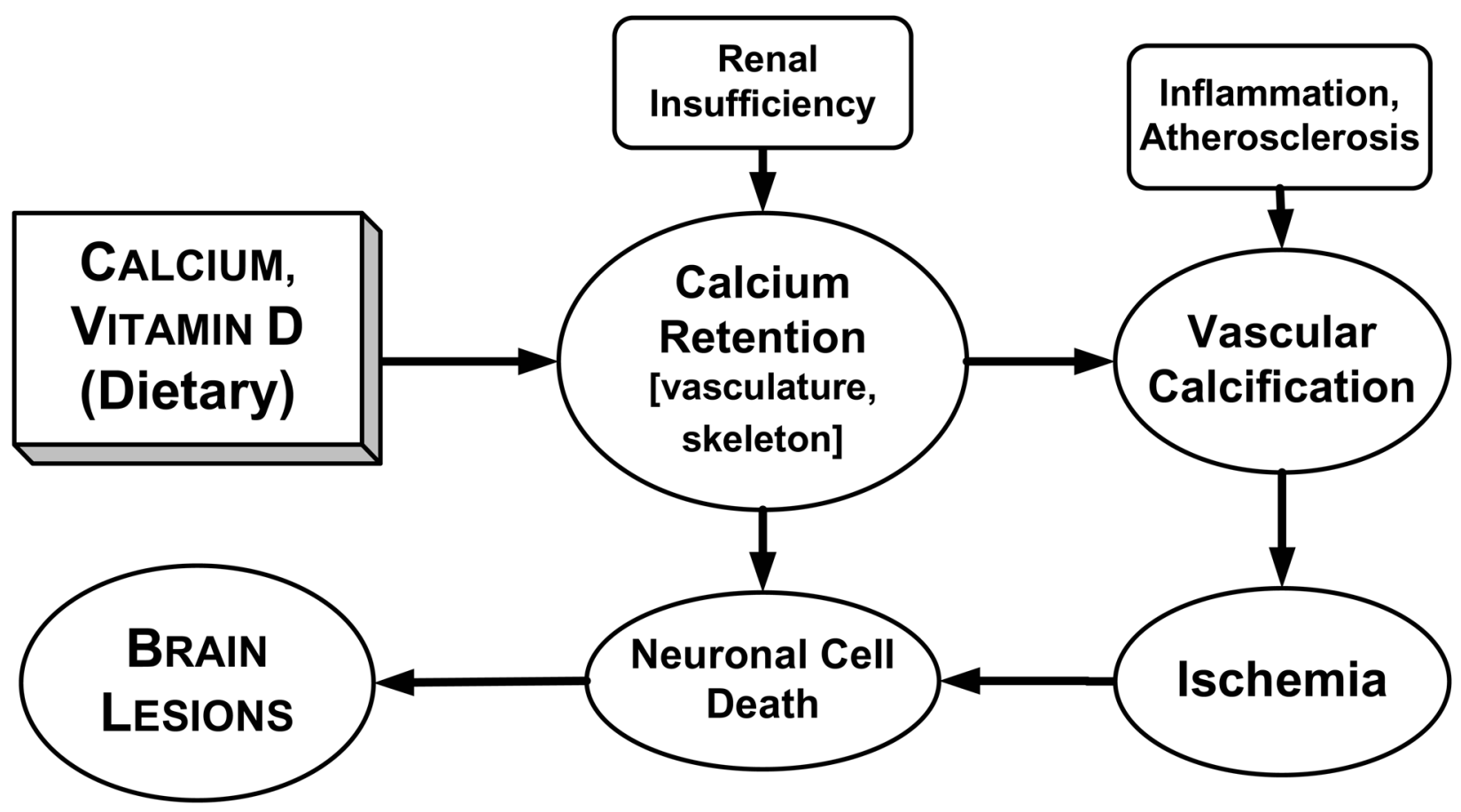

Figure 2. Proposed mechanism for the relationship between calcium and brain lesions 1 ${ }^{1}$ Dietary calcium and vitamin D may promote brain lesions via vascular calcification. High intakes may lead to calcium retention, particularly in the presence of renal disease. Calcium retention combined with atherosclerotic and inflammatory processes may promote vascular calcification which, in turn, may lead to ischemia, neuronal death, and brain lesions. Calcium may also have direct neurotoxic effects which lead to brain lesions. 


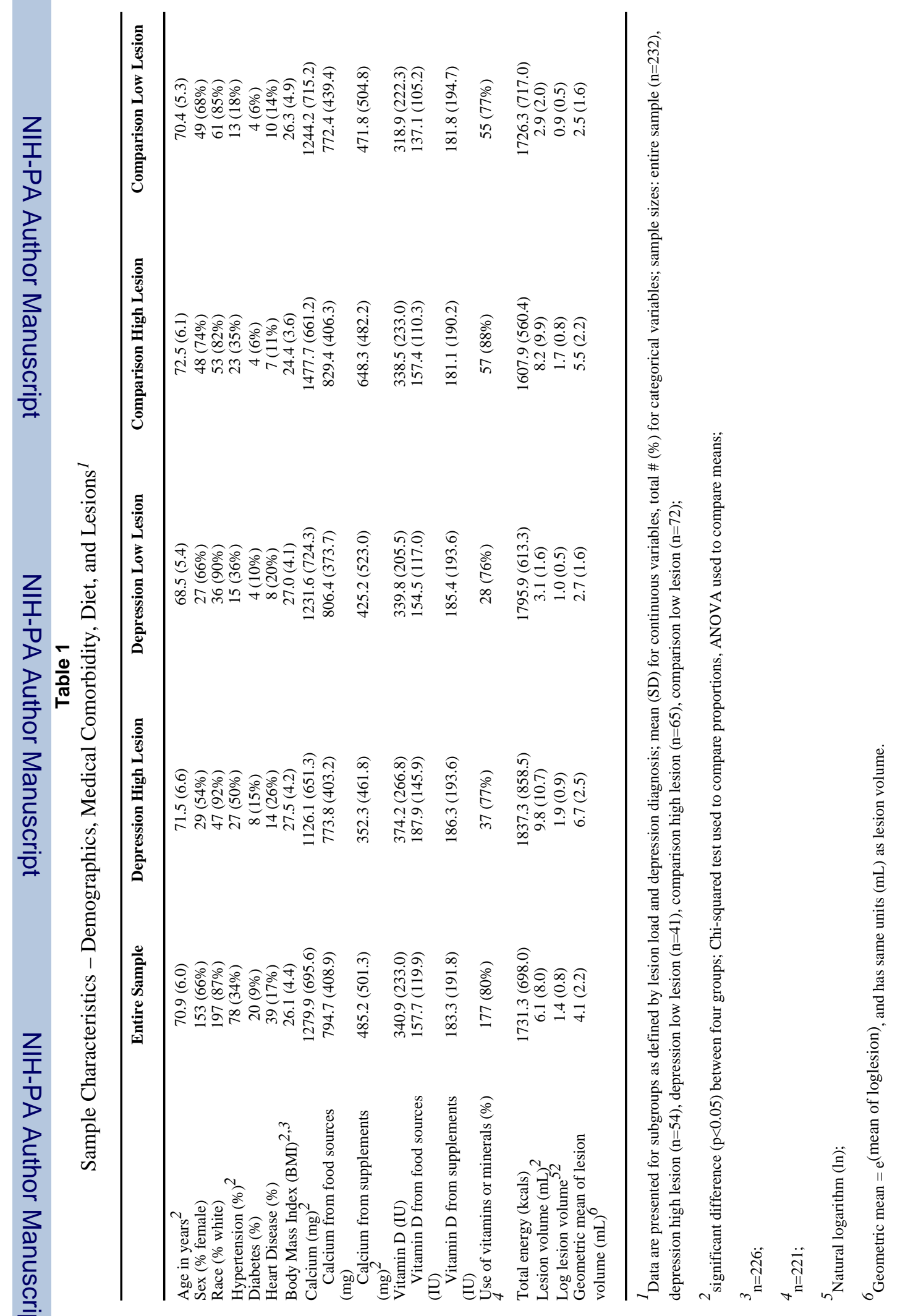

Nutr Res. Author manuscript; available in PMC 2009 January 1. 